\title{
NOTAS PARA UMA ARQUEOLOGIA DAS EXPOSIÇÕES NO BRASIL
}

\author{
Vinicius Spricigo 1
}

\section{Introdução}

Uma arqueologia da curadoria contemporânea ainda precisa ser feita. De qualquer modo, há um consenso de que a curadoria, da forma como exercida atualmente, está ligada historicamente ao colecionismo e à formação de museus na Europa moderna. A etimologia da palavra curar remete ao cuidado, ao ato de tomar conta, e, portanto, está muito mais próxima da necessidade de conservação do que da exposição. Desse modo, entende-se o curador como o profissional atuante junto às instituições responsáveis pela preservação da memória e do patrimônio artístico e cultural. No entanto, a curadoria de arte contemporânea tornou-se notória nas últimas décadas muito mais pela atividade independente de organização de exposições temporárias, estando desvinculada das políticas de inventário institucionalizadas e voltadas, portanto ao mostrar, à exibição.

Enquanto por um lado, a curadoria entendida como a atividade de organizar exposições (no francês o termo usado é commissaire d'exposition e no alemão é ausstellungsmacher), na maioria das vezes ao redor de um tema ou conceito, caminha rumo à sua autonomia em relação às atividades de organização e, sobretudo de conservação de coleções de museus públicos e privados, focando-se, conforme afirma Terry Smith, no contemporâneo, por outro, a curadoria em seu sentido tradicional ainda permanece atrelada à história e à critica de arte. O livro de Smith (2012) trata muito bem das 'conexões e tensões' entre curadoria, critica e história da arte. Enquanto à história caberia o estudo da arte no contexto histórico e social da sua produção, à critica estava ligada à recepção pública das obras no momento da sua apresentação. Esta última caberia ao âmbito da curadoria.

Vale a pena lembrar que, no modo como as conhecemos até a metade do século $\mathrm{XX}$, essas atividades surgiram quase que concomitantemente no século anterior. A história da arte, enquanto disciplina acadêmica estava intrinsecamente associada à

\footnotetext{
${ }^{1}$ Pontifícia Universidade Católica de São Paulo, Brasil.
} 
formação de uma esfera pública da arte e ambas as esferas se formavam ao redor do processo de musealização de obras de arte que ocorreu durante todo o século XIX. Não por acaso, em seu célebre ensaio, 'A obra de arte na época de sua reprodutibilidade mecânica' (1936), Walter Benjamin escolheu como exemplo a Madona Sistina de Rafael. Anteriormente situada no convento de São Sisto em Piacenza, no norte da Itália, sua exponibilidade seria amplificada ao ser mostrada na Königliche Gemäldegalerie em Dresden, principalmente quando em 1855 a obra foi alocada em uma sala especial na recém inaugurada Sempergalerie. A nova encenação, conforme Hans Belting, ocorreu em um momento que representava uma encruzilhada na transição para o romantismo alemão, no qual o valor de culto das obras de arte era aos poucos substituído pelo valor artístico. Consequentemente, muito embora o valor artístico estivesse fundamentado em um discurso critico e historiográfico que se formava naquele momento, estes estavam vinculados ao problema fenomenológico da apresentação de imagens em museus na forma de obras de arte concebidas originalmente para templos religiosos. Com o passar do tempo, o valor de exposição substituiria o valor artístico de caráter transitório.

No início do século XX, com o advento da arte moderna já concebida para os espaços institucionalizados da arte, ocorreu uma verdadeira revolução nos modos de apresentação da arte. Enquanto os salões parisienses ainda tomavam como modelo de apresentação as categorias e hierarquias das academias artísticas, cabiam às grandes feiras internacionais e aos grupos de vanguarda, sobretudo os surrealistas, algumas inovações em termos de display. Nas décadas de 20 e 30 em Berlim, Ludwig Justi, o responsável pela transferência da coleção de arte moderna da National Galerie para o Kronprinzen-Palais, foi o responsável pela criação de um modelo expositivo que tornar-se-ia anos mais tarde paradigmático para a apresentação da arte moderna e que veio a ser conhecido como 'cubo branco' (O'Doherty, 2002). A gestão de Justi transformou a galeria em uma referência para outros museus de arte moderna, como por exemplo, o 'Museum of Modern Art' (MoMA) concebido por Alfred Barr e inaugurado em 1929 em New York. No pós-guerra o modelo expositivo adotado pelo MoMA tornou-se hegemônico, acompanhado por uma historiografia da arte moderna que situava os Estados Unidos como herdeiros de uma tradição europeia. Também a critica de arte deslocava o seu eixo central para a ilha de Manhattan. Configura-se nesse momento uma 'simbiose' entre curadoria, crítica e história da arte. 
Essa relação entraria em crise com as novas vanguardas dos anos 1960, quando, segundo Hans Belting, o enquadramento fornecido pela história da arte moderna já não servia como referência para a produção contemporânea. No mesmo período, também o papel da critica entra em crise, como evidenciado no embate entre os críticos norteamericanos Clement Greenberg e Michael Fried e os artistas minimalistas e conceituais. Esse contexto de profundas mudanças institucionais na esfera da arte assistiria o surgimento da figura do curador independente, personificada na figura do suíço Harald Szeemann. Quando, encarregado da direção artística da Documenta de Kassel de 1972, Szeemann propõe a mudança do slogan da mostra de 'Museu de 100 Dias' para 'Evento de 100 Dias', ele sinaliza uma mudança fundamental no âmbito da curadoria. Certamente podemos afirmar que diretores de museus modernos como Alfred Barr e Ludwig Justi atuaram na região fronteiriça entre curadoria, critica e história da arte, contudo, seria Harald Szeemann que ressaltaria talvez pela primeira vez na história uma maior autonomia da primeira em relação às duas últimas.

No início do século XXI, exposições periódicas e outras exposições temporárias suplantaram o espaço museológico como modelo para a exposição da arte contemporânea. O que se viu foi muito mais a adaptação de museus para a incorporação de modelos de exposição que surgiram fora dos limites do cubo branco. Se tomarmos como exemplo a inauguração da Tate Modern em Londres, as cronologias, movimentos e estilos da arte moderna que forneciam as diretrizes norteadoras para a organização da coleção deram lugar para mostras organizadas ao redor de conceitos e princípios de analogias temáticas ou de linguagem. No Brasil, contudo, onde os museus de arte foram criados muitas vezes oferecendo modelos expográficos extremamente inovadores para a época, como por exemplo, o Museu de Arte de São Paulo projetado por Lina Bo Bardi, foram adaptando-se com o passar dos anos à neutralidade e racionalidade do cubo branco.

\section{Museus de arte no Brasil}

A inauguração (no último sábado dia 05 de Outubro de 2013) da última edição do 'Panorama da Arte Brasileira' do Museu de Arte Moderna de São Paulo, intitulado 'P33: Formas únicas da continuidade do espaço', com curadoria de Lisette Lagnado e curadoria-adjunta de Ana Maria Maia, nos colocam questões interessantes sobre o 
papel da curadoria e dos museus de arte nos dias de hoje. O 'Panorama' é uma espécie de bienal nacional criada pelo MAM, em 1969, com o intuito de restaurar e recolocar o museu no circuito artístico local e formar um novo acervo para uma instituição privada praticamente extinta pouco vinte anos após a sua criação em 1949. O principal motivo da crise do museu era a iniciativa das Bienais Internacionais de São Paulo, do criador do MAM, o empresário ítalo-brasileiro Francisco Matarazzo Sobrinho. Em depoimento sobre o MAM, Mário Pedrosa afirmou: "Não podendo responsabilizar-se pelas duas entidades, ao presidente [Matarazzo] não aparecia outra saída senão a de dissolver a sociedade civil, Museu de Arte Moderna de São Paulo, e entregá-lo, com acervo e bens, à Universidade de São Paulo" (Pedrosa, 1963: 304305). Em suma, Pedrosa dava testemunho de "um dos malogros mais escandalosos e mais tristes da chamada iniciativa privada no Brasil." (Ibidem: 304). Sem o mecenato de Matarazzo e sua coleção inicial, o MAM sobreviveria até os dias de hoje sem um edifício apropriado para a apresentação de sua coleção. Este foi o ponto de partida para a curadora Lisette Lagnado: "Não deixa de ser contraditório perceber que, dentro do parque Ibirapuera, símbolo de um patrimônio moderno do país, que reúne Oscar Niemeyer e Burle Marx, a instituição que supostamente representaria os ideários de uma modernidade racional tem assento em anexo provisório (o Pavilhão da Bahia de Lina Bo Bardi para a $5^{\text {a }}$ Bienal de 1959), que se converteu em sede definitiva" (Lagnado, 2012). Nesse sentido, a curadora subverte a proposta da 'bienal' do MAM, apresentar um panorama da arte brasileira e contribuir para a formação de um acervo, e coloca a própria instituição em questão. Nos seus dizeres: "Panorama significa unir projeto e programa. Diante da demanda de uma economia de construções sustentáveis, todo novo museu surge doravante com uma compreensão de um diálogo orgânico com a cidade. São Paulo teve no Masp um programa pioneiro, quando, nos anos 1950-60, houve uma integração entre o projeto museológico da arquiteta, Lina Bo Bardi, e suas diretrizes pedagógicas. E qual seria o 'laboratório do moderno' hoje?" (Idem)

Artistas e arquitetos reunidos na mostra abordam a questão do museu de arte hoje sob diversos prismas. Não farei aqui um review da exposição, mas gostaria, ao invés disso, de dialogar com o projeto curatorial colocando outras questões. A primeira seria como pôde o MAM perpetuar sua crise transformando-a em modelo de gestão cultural? Em segundo lugar, qual o papel do MAM enquanto instituição privada, na medida em que as iniciativas de Matarazzo de um museu foram assumidas 
e levadas adiante pelo poder público? Como atuam os curadores dentro desse 'dilema' (entre o público e o privado)?

Para iniciar no âmbito da arquitetura, privilegiado por Lagnado em sua proposta curatorial, cito um o trecho de uma carta enviada por Mário Pedrosa ao arquiteto Oscar Niemeyer, datada de 24 de julho de 1958, apresentado um projeto para a construção de um Museu em Brasília. (Pedrosa, 1958). Nesse documento, Pedrosa assinalou os problemas relacionados às tentativas de criação de museus de arte e arte moderna no Rio de Janeiro e São Paulo, indicando a possibilidade de constituição de um acervo de reproduções. Na advertência do crítico:

\begin{abstract}
Nada de se construir em Brasília mais um museu dito de arte ou de arte moderna, nos moldes dos muitos que estão sendo organizados pelo país ou mesmo das tentativas mais importantes do Rio de Janeiro e de São Paulo. Toda gente medianamente informada sobre o assunto sabe quanto são precárias essas tentativas. Averigua-se cada vez mais difícil, senão impossível, criar um museu de artes plásticas do nada e torná-lo digno do nome. Mesmo o Museu de Arte de São Paulo, apesar do esforço feito e das enormes somas despendidas, não é nem um museu de arte 'moderna' nem um museu de arte 'antiga', a despeito de contar em seu acervo com algumas obras importantes no plano mundial. Suas falhas tanto num campo quanto no outro campo são grandes e insanáveis, por maiores que sejam os esforços feitos e os dinheiros que seu organizadores já gastaram ou ainda venham a gastar para suprimi-las. O resultado é que há de ser sempre um museu 'à americana', isto é, incompleto nas suas coleções quanto a uma autêntica representação por escolas e ciclos de arte do passado, e 'híbrido', quer dizer, sem uma especialização caracterizada, de nível verdadeiramente histórico e científico. Quanto aos dois outros do Rio e de São Paulo, mais especializados em matéria de arte moderna ou contemporânea, muito deixam a desejar quanto às suas coleções e acervos, a despeito dos esforços sobre-humanos e patrióticos de suas direções. Mais um museu similar em Brasília viria apenas aumentar a lista dos museus de concorrência aos já existentes, sem maiores e mais positivos resultados.
\end{abstract}

Hoje, quando os acervos dos principais museus do mundo estão disponíveis para visualização através da rede mundial de computadores, o projeto de Pedrosa parece anacrônico. Mais anacrônica ainda foi a retomada dos planos para a construção de um museu para o Conjunto Cultural da República, em Brasília, concluído em 2006. O fato de Brasília ser uma Capital Nacional sem um Museu (Fraser, 2003) revela ainda o 'malogro' da iniciativa pública na tarefa de criação e sustentação de museus de arte no país.

Poucos metros da sede do MAM sob a marquise do Ibirapuera, no Pavilhão da Bienal, encontra-se uma exposição celebratória dos trinta anos da Bienal de São Paulo. A mostra '30 x Bienal', com curadoria de Paulo Venâncio Filho, apresenta um 'panorama' da arte brasileira a partir dos artistas apresentados nas trinta edições da 
bienal. Novamente, não farei um review da exposição. Gostaria somente de sublinhar o fato de que nenhum museu brasileiro seria capaz de apresentar, a partir de suas coleções, um mostra tão representativa da arte moderna e contemporânea no Brasil como fez a Bienal ao longo de seis décadas. Nem mesmo o MAC-USP que agora instala-se do outro lado da avenida em frente ao Ibirapuera. Em suma ainda cabe à Bienal de São Paulo, 60 anos após a sua criação, suprir a carência de São Paulo e do Brasil por museus de arte, 'dignos do nome', conforme a análise de Mário Pedrosa.

No que diz respeito ao MAM, isso ratifica ainda o diagnóstico feito Pedrosa há quase cinquenta anos sobre o anacronismo do mecenato contemporâneo:

[...] se o mecenas de hoje é uma figura retardatária porque não pode, por sua psicologia mesmo, deixar de subordinar tudo, mesmo as coisas mais elementares e indispensáveis, aos caprichos da própria vontade, teimando em fazer das instituições culturais de essência naturalmente pública, que acontece financiarem, propriedade sua, tampouco isso significa que o papel da iniciativa particular nesse domínio esteja encerrado. Ao contrário, cabe-lhe, pelo menos, no regime teoricamente livre em que vivemos uma tarefa primordial no desenvolvimento cultural da cidade.

Contudo, se Pedrosa fez a afirmação acima tendo em vista a entrega "exclusivamente aos Estados dos encargos por todas as atividades culturais e artísticas", não imaginou o critico que mais tarde o Estado entregaria à sociedade civil a gestão dos recursos estatais dedicados à cultura, pelo viés do uso de recursos das leis de incentivo à cultura e pelas chamadas OCIPs (Organizações da Sociedade Civil de Interesse Público). No período de redemocratização da sociedade brasileira já se anunciava a renúncia do Estado na proposição de políticas pública na área e deixava à iniciativa privada os encargos da política cultural, incentivada pelas leis de renúncia fiscal. (Oliveira, 2009)

\section{As exposições de arte no século XXI}

Um exemplo (polêmico) de uma exposição no início do século XXI poderia nos ser útil aqui na discussão da atuação do curador dentro de modelos de gestão cultural atualmente empregado no Brasil. Na ocasião da $23^{\text {a }}$ Bienal de São Paulo, realizada em 1996, Aracy Amaral afirmou o seguinte: 
O lema das Bienais agora é 'o maior é melhor' ou 'think big', embora se diga que não há dinheiro na praça, que o mercado de arte está parado (?), e que não há público para artes visuais _ a cada dia mais restritas aos iniciados. Esta é a contradição com que novamente nos deparamos: esta Bienal, em particular, foi evento para uma pequena elite, mobilizando com força impressionante os 'mass media'. Como explicar o porte de promoções envolvendo socialites/empresários? $\mathrm{O}$ meio intelectual e cultural ficou de longe. Até se prescindiu dele, como de algo incômodo, pois poderia levantar questões que importunassem o desejado ar de festa. A resposta talvez seja a entrada maciça da iniciativa privada a demandar 'retorno', palavra-chave para investidores. (Amaral, 2006)

Esse modelo de gestão cultural focado em mega-exposições, as chamadas 'blockbusters', foi aplicado à Bienal, quando assumiu a diretoria da Fundação Edemar Cid Ferreira,entre 1992 e 1996. Após o fracasso da $21^{\text {a }}$ Bienal de 1991, que buscou restabelecer um sistema superado de submissão de propostas segundo Rodrigo Naves (2005), esse modelo de gestão cultural seria não somente uma solução para devolver prestígio e grandiosidade à Bienal de São Paulo, atraindo o grande público, mas igualmente para inserir o Brasil no mapa da arte global que apenas começava a ser desenhado. Ferreira foi responsável inclusive pela representação brasileira na $49^{\mathrm{a}}$ Bienal de Veneza. Ademais, um dos projetos arquitetônicos apresentados no 'Panorama' do MAM, de autoria de Oscar Niemeyer, era uma proposta para a construção de um prédio anexo ao Pavilhão da Bienal, para ampliar a área expositiva da mostra. À Bienal caberia, portanto compensar a fragilidade das instituições artísticas no Brasil, realizando grandes mostras internacionais.

Contudo, esse modelo de gestão cultural conduziu a Fundação Bienal a um beco sem saída. Segundo Naves (2005), o sucesso de Edemar Cid Ferreira na direção da Bienal, aumentando consideravelmente o seu público, levou o banqueiro a criar no interior da instituição a Associação Brasil +500 , rachando a Bienal 'ao apoiar o adiamento da $25^{\text {a }}$ edição, que coincidiria com sua "Mostra do Redescobrimento" 2

\footnotetext{
${ }^{2}$ A criação da Associação Brasil +500 e a realização da Mostra do Redescobrimento - Realizada no Parque do Ibirapuera, em São Paulo, entre 7 de abril e 23 de setembro de 2000, a Mostra do Redescobrimento foi visitada por 1,8 milhão de pessoas - inviabilizaram a realização da exposição em 2000, sob a curadoria de Ivo Mesquita. O motivo declarado foi a falta de recursos e aparelho institucional para ambas as exposições, pois a mostra do Redescobrimento foi a maior exposição de arte já montada no Brasil, ocupando grande parte do complexo projetado por Niemeyer no parque Ibirapuera e totalizando 60 mil metros quadrados, o que consumiu boa parte dos recursos das empresas reservados para a Lei Rouanet. A exposição foi gigantesca: ocupou entre 22 de abril a 21 de setembro de 2000 três pavilhões do parque Ibirapuera (Pavilhão Ciccillo Matarazzo - Bienal Pavilhão Lucas Nogueira Garcez - Oca, Pavilhão Padre Manoel da Nóbrega - Museu Afro Brasil), ocupando 50 mil m2, reuniu em torno de 15 mil obras, editou 14 catálogos, teve orçamento de 40 milhões (mediante lei de incentivo fiscal), público de 1.000 .000 de pessoas e itinerou para 11 cidades brasileiras e para outras 20 no exterior (Argentina, EUA, Inglaterra, França, Portugal e Espanha). O projeto de Edemar Cid Ferreira, que transformou a Associação na Brasil Connects, incluiu ainda a itinerância da mostra, que percorreu diversas cidades no Brasil e no mundo, como Buenos Aires, Lisboa, Londres e Paris, antes
} 
Vale lembrar que esse racha levaria a presidente do MAM-SP, Milu Villela, à renuncia sua candidatura à presidência e ao conselho da Bienal. Villela também rivalizava com Ferreira pela ocupação do prédio curvo do Parque Ibirapuera, atualmente conhecido como 'oca', concedido, após a 'Mostra do Redescobrimento' à 'Brasil Connects', novo nome dado à Associação Brasil +500 , para a realização de grandes mostras temporárias.Nesse sentido, a compreensão do atual 'Panorama' apresentado no MAM requer não somente o questionamento de concepções arquitetônicas de museu, de questionamentos ao espaço do cubo branco, mas também da gestão do patrimônio cultural no Brasil e das exposições de arte no século XXI.Trata-se de uma mudança fundamental, uma 'virada global' na concepção de museus na forma como herdados do século XIX, mas no caso brasileiro, isso remete também a precariedade institucional à qual nos referimos acima.

Paradoxalmente, durante o processo de organização da exposição em comemoração aos '500 Anos de Descobrimento', o curador Nelson Aguilar recuperou o projeto de Mário Pedrosa para o Museu das Origens ${ }^{3}$. O projeto foi formulado por Pedrosa na ocasião da destruição do Museu de Arte Moderna do Rio de Janeiro, devido ao incêndio ocorrido em 1978. Em sua proposta, ele afirmou que o momento (do puro mecenato) e a ideologia que levou à criação dos Museus de Arte no Brasil no pós-guerra haviam mudado, e, portanto com o auxílio do Estado ele previa a fundação

de chegar ao Guggenheim de Nova Iorque, em março de 2002, um ano após ter organizado a representação brasileira na Bienal de Veneza em parceria com a Fundação Guggenheim, que anunciava planos de abrir uma de suas "franquias" na cidade do Rio de Janeiro. Cf. BARROS, Stella Teixeira de. Males de nascença. In: 50 Anos de Bienal Internacional de São Paulo, Revista USP, n. 52. Dez./fev 2001-2002: 64-71.

${ }^{3}$ Aguilar usou o quadro conceitual definido por Pedrosa par os 12 segmentos de sua Mostra do Redescobrimento: Arqueologia - curadoria Maria Cristina Mineiro (Museu de Arqueologia e Etnologia da USP) e Cristina Barreto (curadora independente); Arte Indígena - curadoria Lúcia Hussak van Velthem (Museu Paraense Emílio Goeldi, em Belém), José Antonio Braga Fernandes Dias (Faculdade de Belas Artes da Universidade de Lisboa), Regina Polo Miller (Instituto de Artes da Unicamp) e Luiz Donizete Grupione (independente); Séculos XVII e XVIII - curadoria Myriam Andrade Ribeiro de Oliveira (Universidade Federal do Rio de Janeiro e Iphan/RJ); Século XIX - curadoria Luciano Migliaccio (Faculdade de Arquitetura e Urbanismo da USP) e Pedro Xexeo (Museu Nacional de Belas Artes, no Rio); Negro de Corpo e Alma - curadoria Emanoel Araújo (Pinacoteca do Estado de SP); Arte Afro-Brasileira curadoria François Neyt (Universidade de Louvain-la-Neuve, Bélgica), Kabengele Munanga (Centro de Estudos Africanos da USP), Maria Heloísa Leuba Salum (Museu de Arqueologia e Etnologia da USP) e Catherine Vanderhaegue (independente); Arte Popular - curadoria Emanoel Araújo (Pinacoteca do Estado de SP) e Frederico Pernambuco de Mello (Fundação Joaquim Nabuco, em Recife); O Olhar Distante - curadoria Jean Galard (Museu do Louvre, em Paris) e Pedro Aranha Corrêa do Lago (independente); Imagens do Inconsciente - curadoria Nise da Silveira e Luiz Carlos Mello (ambos do Museu de Imagens do Inconsciente, no Rio); Arte Moderna - curadoria Nelson Aguilar (Unicamp e Fundação Bienal), Franklin Espath Pedroso (independente) e Maria Alice Milliet (independente); Arte Contemporânea - curadoria Nelson Aguilar (Unicamp e Fundação Bienal), Franklin Espath Pedroso (independente) e Glória Ferreira.

Iluminuras, Porto Alegre, v. 15, n. 35, p. 222-236, jan./jul. 2014 
do 'Museu das Origens', formado por cinco museus: Museu do Índio; Museu de Arte Virgem (Museu do Inconsciente); Museu de Arte Moderna; Museu do Negro; Museu de Artes Populares. Nota-se na proposta de Mário Pedrosa uma inversão de perspectiva em relação o foco adotado pelo museu: "Toda a arte moderna inspirou-se na arte dos povos periféricos, portanto nada mais adequado para o Museu de Arte Moderna do Rio de Janeiro do que apresentar essa arte que temos em abundância, ao lado de um acervo de arte contemporânea brasileira e latino-americana". (Pedrosa, 1978: 309)

Certamente, num país que obliterou aquelas expressões artísticas que fugiram aos cânones ditados pela arte ocidental, incluir esses grupos em uma celebração oficial foi vista uma oportunidade de dar visibilidade às figuras até então marginalizadas. Entretanto, o discurso curatorial ainda se norteava pelas questões da miscigenação das três raças e seu racismo latente, bem como para uma visão estetizante da hibridação cultural que reforçava uma visão eurocêntrica dos processos de produção cultural no Brasil. Ademais, apesar da abordagem interdisciplinar, rompendo com paradigmas historiográficos e fronteiras entre disciplinas (história da arte, arqueologia, antropologia, sociologia etc.), e da inclusão das artes ditas populares, afro-brasileiras e do inconsciente, foi mantida uma concessão celebratória, focada, no final das contas, no debate sobre a identidade brasileira. Nas palavras de Ana Mae Barbosa (2001): "Muito se falou de identidade, mas nada se ouviu falar sobre pós-colonialismo".

As principais polêmicas sobre a Mostra do Redescobrimento giraram em torno da apresentação das obras no espaço expositivo (display) ${ }^{4}$.Contestava-se principalmente:

[...] uma forma de exposição que colocava a arte em segundo plano, em beneficio da grandiosidade dos eventos, com a qual sua visibilidade e prestígio cresceriam junto com os negócios. Há aqui uma inversão de papéis que convém analisar. Certamente, a dimensão transgressora, de ampliação dos significados e experiências, ainda que ameaçada pelo conservadorismo pós-moderno, permanece uma componente decisiva das grandes obras de arte. O que Edemar Cid Ferreira fez foi conferir, de maneira caricatural e exponenciada, essa dimensão aos eventos que comandou, que assim adquiriam maior relevância do que os trabalhos que abrigavam. O exemplo mais gritante talvez tenha sido a intervenção de Bia Lessa no setor de arte barroca da Mostra do Redescobrimento, no qual o mar de flores de papel mal permitia que se vissem as obras expostas. E basta folhear os jornais

${ }^{4} \mathrm{O}$ debate sobre a exposição se limitou aos artigos, especialmente àqueles publicados em edição especial da Folha de São Paulo (20/04/2000) e do Caderno de Resenhas do mesmo jornal (12/08/2000), 
da época para ver quem ganhou mais espaço na mídia no período, se as obras ou a cenografia. (Naves, 2005)

O critico Rodrigo Naves assinala ainda o fato de que isso seria uma tendência mundial na qual o Brasil participava, mas em outros países "o apelo proporcionado pelas grandes exposições é contrabalançado pelas coleções permanentes, que possibilitam um convívio e uma experiência mais adequados aos trabalhos de arte, sem falar em todo um sistema educacional que torna aquele contato mais produtivo. As obras de arte já incorporadas à história da arte, ainda que continuem a instigar, passam a funcionar também como cultura, como compreensão e manifestação da história e de seus dilemas" (Idem).

Essa polêmica em torno da cenografia e ambientação das obras na mostra revela um purismo que permanece enraizado em certas correntes acadêmicas e discursos críticos fundamentados nos paradigmas modernistas da história da arte. Essa visão conservadora vincula assim tal mudança nos modos de apresentação da arte no século XXI ao modo como as políticas culturais adotadas durante os primeiros anos de globalização haviam reconfigurado completamente a dinâmica do sistema das artes no Brasil, propiciando não somente a emergência da figura do curador, mas antes de mais nada, a sua atuação dentro de uma nova lógica de 'espetacularização' e 'mercantilização' da cultura.

Aparentemente todo esse sistema parecia entrar em colapso, juntamente com a falência do Banco Santos e a prisão de Edemar Cid Ferreira: "Quando a fonte secou, cessaram todas as mostras, toda a aparente pujança de nossa arte e da capacidade de realizar mostras internacionais. Num país em que a arte contemporânea ainda é vista como simples arbítrio e futilidade, não poderia haver maior desserviço" (Idem). Nos anos que seguiram a Bienal deu continuidade aos seus ciclos de crise e retomada de prestígio, o MAM seguiu sendo um museu em estado provisório permanente, enquanto, no recém inaugurado 'novo MAC', obras da coleção particular de Edemar Cid Ferreira sob a guarda do museu por decisão judicial preenchem temporariamente as lacunas de uma coleção que em termos de arte contemporânea fica à sombra de seu acervo de arte moderna. Enquanto acumulam-se os fracassos tanto da iniciativa pública e privada na consolidação daquela consideradas como as principais instituições artísticas brasileiras, ainda sob a marquise do Ibirapuera, a 'invisibilidade' 
do museu Afrobrasil, de menor impacto midiático e mercadológico do que os demais, persiste a nos lembrar que vivemos uma 'virada global' e 'pós-colonial'.

\section{Gestão cultural e curadoria: entre o público e o privado}

O papel da gestão cultural é colocar em prática objetivos definidos por uma determinada política cultural com a finalidade de promover a produção, distribuição, troca e uso de bens culturais. A gestão cultural é, portanto a mediação entre os produtores, o mercado e os incentivadores e o público, cabendo ao Estado, em alguns casos, o papel de gestor ou de incentivador direto ou indireto. Em casos nos quais a iniciativa privada ou a sociedade civil deixa de atuar sob as políticas culturais definidas pelo Estado, os objetivos da gestão cultural passam a ser definidos por um planejamento estratégico e por interesses de mercado ou de grupos específicos. No Brasil, contudo, as distinções entre público e privado são tênues. Existem instituições públicas e privadas geridas pela sociedade civil, pelas chamadas OCIPs, com aportes de recursos diretos e indiretos, via Lei Rouanet. Quando isso acontece, o Estado transfere à iniciativa privada não somente a gestão de projetos culturais, mas também a definição dos objetivos a serem alcançados. Embora os interesses das iniciativas privadas se digam públicos, eles não são discutidos e decididos publicamente dentro de uma perspectiva mais ampla, mas dentro de um pequeno grupo de gestores envolvidos em projetos específicos. Desse modo, o poder público delega à sociedade civil a gestão cultural e as políticas culturais concentram-se no incentivo fiscal para o patrocínio privado. É nessa rede social que se estabelece entre artistas, mercados e instituições, na qual gradativamente deixa de ser primordial o papel do poder público, que a atuação do curador acontece.

Discutimos anteriormente, em uma perspectiva histórica, as transformações no âmbito das exposições de arte no início do século XXI, tomando como exemplo o caso brasileiro. Por fim, seria importante analisar como esses diferentes momentos históricos, moderno e contemporâneo, correspondem diferentes concepções de gestão cultural e de curadoria. Poderíamos dizer, a grosso modo, que em um primeiro momento, a ênfase está no patrimônio, nas coleções e nas instituições, enquanto no segundo, a ênfase está na exposição.

No primeiro caso, existe uma participação maior do Estado na gestão cultural. Vale lembrar que a ideia de patrimônio surge com o Estado Nação moderno. A 
memória cultural está na maioria das vezes ligada à identidade cultural de um país e um povo e para o Estado interessa a preservação da memória e do patrimônio como importantes elementos da unidade nacional. Utilizando recursos humanos e materiais o Estado desenvolve programas de fomento à produção cultural, de mediação entre a produção cultural e o público ou de formação de público. O Estado pode incentivar programas que estão de acordo com sua política cultural ou, através de renúncia fiscal, incentivar os incentivadores privados alinhados com a sua política. Importante frisar que aquilo que deveria ser analisado não seria somente a questão da participação da iniciativa privada no âmbito da cultura. Essa participação, apesar do anacronismo do mecenato, é salutar e até mesmo necessária, conforme assinalou Mário Pedrosa. Contudo, há uma diferença primordial entre uma burguesia nacional, engajada na construção de um projeto cultural para um país, conforme assistimos na criação de museus no período moderno, e a participação atual de empresas privadas no patrocínio de eventos de arte contemporânea. O problema principal é, portanto a despolitização da esfera da cultura.

Ademais, essa despolitização da esfera da cultura acompanha a mudança histórica à qual estamos nos referindo, ou seja, a passagem de um estágio no qual a atenção era dada ao bem cultural em si, sua preservação física e organização enquanto patrimônio cultural, para a promoção do acesso à cultura cada vez mais amplo e irrestrito ao público, criando assim condições para o seu entendimento através da formação e educação. Os grandes museus nacionais mundo afora se deram conta de que a produção artística contemporânea não se presta ao discurso da identidade nacional e substituíram seus programas por eventos ligados principalmente à globalização cultural. Aqueles museus que ainda conseguem manter políticas de aquisição mesmo com os altos preços do mercado de arte contemporânea tratam agora de incluir obras de artistas do mundo todo em suas coleções. Se o 'internacionalismo' da arte moderna se convertia em patrimônio nacional, apesar das polêmicas, a arte contemporânea, conforme constata Hans Belting, está fadada a ser um fenômeno global.

No entanto, no caso brasileiro, como um patrimônio cultural não foi constituído a contento nem pelo poder público, tampouco pela iniciativa privada, a ampliação do acesso a cultura e a formação e educação ficam comprometidos. Além disso, talvez pela necessidade ainda presente de consolidação de instituições locais, os discursos sobre globalização e pós-colonialismo não substituíram uma perspectiva 'brasileira'. 
No caso da exposição ' 30 x bienal', por exemplo, a análise do papel histórico da Bienal de São Paulo se resume à sua contribuição para a arte no Brasil, sem adentrar a perspectiva internacional da própria mostra bienal. Também o MAC-USP, ao inaugurar a sua nova sede, deixa claro, ao apresentar suas novas aquisições e uma 'síntese' de sua coleção, sua incapacidade de apresentar um 'panorama' da arte contemporânea em uma perspectiva global. À ausência de nomes estrangeiros entre as novas aquisições, somam-se as lacunas que a coleção apresenta também no que diz respeito à arte contemporânea produzida no Brasil.

Nesse contexto, o processo de espetacularização e mercantilização da cultura global se tornam muito mais evidente e problemático, pois o poder público não criou as condições materiais para facilitar o acesso à cultura e abre mão de desenvolver políticas públicas para a área. Por outro lado, a iniciativa privada toma em suas mãos a tarefa de formação e educação do público, dependentes, no entanto dos recursos público e dos aportes financeiros dos patrocinadores provenientes das renúncias fiscais. Estes, por fim, veem na cultura um ótimo negócio para a divulgação de suas marcas, vinculando-as ao prestígio da alta cultura sem a necessidade de patrocínio direto.

Nesse cenário em transformação, a atuação do curador independente é muito distinta daquela do curador vinculado a uma instituição pública ou privada. Neste último, muito embora exista uma ambivalência entre os interesses daqueles responsáveis pela gestão cultural e também do modelo de gestão cultural, a concepção da gestão cultural e da curadoria partem da premissa de que o primordial é zelar pela memória e pelo patrimônio cultural. Há um consenso entre o poder público e a iniciativa privada da importância da formação e preservação de coleções e da criação de museus. As exposições, a educação e a formação do público são atividades secundárias, decorrentes do papel patrimonialista da gestão cultural. Basta lembrar dos casos citados dos museus de arte moderna e contemporânea de São Paulo cujas coleções são até hoje pouco conhecidas pelo público. Outro aspecto fundamental é o fato das coleções corresponderem a uma certa narrativa histórica, em muitos casos de cunho nacionalista. O curador apresenta-se nesse sentido não somente como um especialista em arte, mas seu discurso deve estar alinhado com os interesses do Estado e da burguesia local na construção de um projeto nacional. 
Certamente museus também realizam exposições temporárias ou temáticas com obras de seus acervos ou com empréstimos de outras coleções, mas na maioria das vezes estas são pensadas dentro de um perfil institucional estabelecido a partir da própria coleção do museu. Por esse motivo, o curador seria um especialista na coleção de determinada exposição e trabalharia sempre tendo esta como seu ponto de partida. A rigor, embora as fronteiras entre gestão cultural e curadoria sejam tênues, esse curador não seria um gestor ou administrador cultural, não cabendo dentro de suas atribuições estabelecer relações com o mercado e o poder público. Defende-se assim uma autonomia paradoxal da atividade do curador, na qual ele teria como foco de seus interesses os produtores e produtos artísticos. Em suma, o curador atua dentro de uma instituição como mediador entre o artista e o público. Assim justifica-se também a atuação do curador como crítico. A afinidade do curador com a produção artística é um pré-requisito importante ao lado do seu conhecimento especializado na história da arte.

O curador independente mantém o seu papel como mediador, mas a sua ênfase está muito menos no patrimônio e mais na exposição. Nos casos citados da 'Mostra do Redescobrimento' e da Bienal de São Paulo, os curadores obtiveram um grande êxito em reunir temporariamente no parque Ibirapuera obrar que poucas instituições brasileiras seriam capazes de adquirir e manter permanentemente em suas coleções. Ademais, essas mostram tiveram grande visibilidade pública, muita acima da média dos museus locais. Contudo, isso não contribui diretamente para a formação de coleções permanentes e projetos educativos focados em um patrimônio nacional. As exposições temporárias seriam nesse sentido muito mais apropriadas à curadoria que se concentra no contemporâneo, sem a preocupação de fixar sua permanência. As bienais, por exemplo, ao abandonarem os modelos de representações nacionais e incluírem em seus programas debates acerca da globalização cultural e proveniente dos discursos pós-coloniais, converteram no início do século XXI como as principais exposições de arte contemporânea. Forneceram ainda plataforma para os mais importantes projetos curatoriais contemporâneos e foram responsáveis para colocar em relevo a figura do curador. Serão elas, apesar das polêmicas acerca da mercantilização e espetacularização da cultura global, que fornecerão um sitio privilegiado para uma arqueologia da curadoria contemporânea. 


\section{Referências}

AMARAL, Aracy. Grandiloqüência e Marketing. In: Textos do Trópico de Capricórnio: artigos e ensaios (1980-2005) - v. 3: Bienais e artistas contemporâneos no Brasil. São Paulo: Ed. 34, 2006.

BARBOSA, Ana Mae. 500 anos: comemorações ou celebrações? Disponível em: http://www.vitruvius.com.br/revistas/read/arquitextos/01.011/900

FRASER, Valerie (2003). Brasília: uma capital nacional sem um museu nacional. Disponível em www.forumpermanente.org

LAGNADO, Lisette. Curadora Lisette Lagnado fala sobre o Panorama da Arte Brasileira, Especial para a Folha de São Paulo, 09.12.2012.

NAVES, Rodrigo. As Artes Como Abre-Alas, O Estado de São Paulo, 02 de outubro de 2005. Disponível em: www.forumpermanente.org

OLIVEIRA, Lúcia Maciel (2009). Que políticas culturais? Disponível em: www.centrocultural.sp.gov.br

PEDROSA, Mário. Depoimento sobre o MAM. In: Arantes, Otília (Org.). Política das Artes. São Paulo: Editora da USP, 1995, pp. 299-208. (Conferência de 21.03.63, publicada em $O$ Estado de São Paulo, 24.03.63).

Projeto para o Museu de Brasília. In: ARANTES, Otília (org.). Política das Artes: Mário Pedrosa. São Paulo: Edusp, 1995, pp. 287-294.

SMITH, Terry. Thinking Contemporary Curating. New York: Independent Curators International, 2012. 